\title{
TECHNICAL CONSIDERATIONS IN LOW-COST HERITAGE DOCUMENTATION
}

\author{
A. Murtiyoso ${ }^{1}$, P. Grussenmeyer ${ }^{1}$ and D. Suwardhi ${ }^{2}$ \\ ${ }^{1}$ Photogrammetry and Geomatics Group, ICube Laboratory UMR 7357, INSA Strasbourg, France - \\ (arnadi.murtiyoso, pierre.grussenmeyer)@insa-strasbourg.fr \\ ${ }^{2}$ Remote Sensing and GIS Group, Bandung Institute of Technology, Indonesia - deni@gd.itb.ac.id
}

\section{Commission II}

KEY WORDS: heritage, photogrammetry, low-cost, drone, $360^{\circ}$ camera

\begin{abstract}
:
The use of photogrammetry in 3D heritage documentation has matured over the recent years. In the same time, many types of sensors have also been developed in the field of imaging. While photogrammetry is considered as a low-cost alternative to TLS, several options exist in terms of sensor type with trade-offs between price, ease of use, and quality of resolution. Nevertheless, a proper knowledge on the acquisition and processing is still required to generate acceptable results. This paper aims to compare three photogrammetric sensors, namely a classical DSLR camera, a drone, and a spherical $360^{\circ}$ camera in documenting heritage sites. Main comparison points include quality of the bundle adjustment and quality of the dense point cloud. However, an important point of the paper is also to determine whether a sensor at a given cost and effort is enough for documentation purposes. A TLS point cloud data was used as a common reference, as well as control and check points issued from geodetic surveying. In the aftermath of the comparison, several technical suggestions and recommendations were proposed as regards to the use of each sensor.
\end{abstract}

\section{INTRODUCTION}

Heritage documentation has seen a boom in the past two decades due to various reasons, including the development of $3 \mathrm{D}$ sensors and $3 \mathrm{D}$ data processing. Although 2D data remains pertinent in the documentation process, 3D data is becoming more and more ubiquitous in representing heritage sites and objects. This increase in interest for heritage documentation is a very positive progress in the archiving of many historical sites and objects. While 3D techniques provide a more complete and objective recording of objects than their $2 \mathrm{D}$ counterpart, it is not by any means a low-cost solution for heritage documentation. This is very important especially when discussing the heritage documentation domain, where cost often remains a very important constraint. Practical sensors such as laser scanners provide easy, fast, and accurate results, but remain an expensive sensor especially for the heritage domain. Photogrammetry provides a more low-cost alternative, however careful considerations must be taken when performing it. Main technical considerations include the choice of sensors, the acquisition pipeline, the geometric quality, as well as the dense point cloud quality. The main question that we wish to answer in this paper is how far low-cost photogrammetric techniques can be used to record heritage objects, and whether the results are satisfactory enough for documentation purposes as regards to the cost. Although recent trends go towards the integration of sensors to complement each other's disadvantages (Farella et al., 2019; Murtiyoso et al., 2018), the objective of the paper is to see how far we may go when using specific low-cost sensors in the case of heritage recording.

In this paper, three relatively low-cost photogrammetric sensors will be compared in terms of ease of acquisition, geometrical quality, and dense point cloud quality. The first sensor is a classical DSLR camera (Canon 5DS R). This is arguably at the higher-end of the low-cost sensor tier, and its acquisition pipeline has been refined over the years through classical close range photogrammetry methods. The second sensor is an aerial drone, the DJI Phantom 4. The drone was used to acquire close range images following close range photogrammetry guidelines. The last sensor is a Ricoh Theta V $360^{\circ}$ camera, which while presents much lower quality images than the other two sensors, has the large advantage in terms of cost and ease of acquisition. Terrestrial laser scanning (TLS) point cloud was also performed in order to present a reference to quantify the quality of the geometry as well as the dense point cloud generated from each photogrammetric sensor. Previous work with close range photogrammetry using drones can be seen in Murtiyoso and Grussenmeyer (2017), while $360^{\circ}$ images were used in Barazzetti et al. (2019).

The case study used in this paper is an acquisition mission performed on the Candi Sari site in Yogyakarta, Indonesia (Figure 1). Javanese temples ("candi") are religious structures dating to the Middle Ages (9th to 15th century) and are either Buddhist or Hindu in nature. Most of these structures lie in the Indonesian provinces of Yogyakarta and Central Java, with some other notable examples existing in other provinces as well (Degroot, 2009). They are generally identified by the use of volcanic rocks as the main building material and frequently adorned by intricate bas-reliefs. Although these monuments are well documented in traditional mediums such as drawings, only few studies have been conducted on their 3D documentation from a geomatics point of view. Several examples of notable cases include the work of (Herbig et al., 2019; Hidayat and Cahyono, 2016; Suwardhi et al., 2015). With this background in

\footnotetext{
* Corresponding author
} 
mind, a 3D acquisition mission was carried out in November 2018 within the framework of the Franco-Indonesian Partenariat Hubert-Curien (PHC) "Nusantara" and SAMEPerancis to document Candi Sari, which presents a typical example of a Javanese temple. The temple's dimensions are around 20 meters by 14 meters in a rectangular shape. The interior consists of three chambers with visible remains of a possible second storey, giving the archaeological assessment that the temple was a vihara or a monastery for Buddhist monks rather than a pure place of worship (Degroot, 2009). The interior is also notable for its niches that were possibly intended for images of garbha-dhatu deities, as is the case of Candi Mendut, another Javanese-style Buddhist temple. Some sculptures adorn the exterior façade, including an imposing sculpture of the traditional kala above the entrance and the niches in the interior.

This paper will first present a summary of the use of photogrammetry as a low-cost solution to heritage documentation. It will be followed by a description of the case study, as well as the generated results and comparisons against the reference data. Finally, at the end of the paper, recommendations on technical aspects for heritage documentation using low-cost photogrammetric sensors will be proposed based on the observations of the said case study.

\section{RELATED WORK}

Heritage documentation is often characterised by the myriad of 3D sensing techniques available in the market today, as well as difficulties in maintaining a balance between cost, effort, and precision in choosing them. As technical developments advance, many which were cost prohibitive in the past have become more and more low cost (e.g. transition from analogue metric cameras to digital non-metric cameras in photogrammetry). That being said, the laser scanning technology has more or less become the standard solution in heritage documentation (Chiabrando et al., 2017; Herbig et al., 2019; Lachat et al., 2017; Pöchtrager et al., 2018). The technology has been around since 1980s and was a revolutionary technology in the domain of 3D mapping. Contrary to traditional total stations, the TLS technology enables the recording of the environment in a fast and relatively accurate manner while being fairly easy to use (Murtiyoso et al., 2018).

Photogrammetry on the other hand, is an older technology dating back to the analogue era. In the past two decades, however, it has seen resurgence as image processing algorithms advanced significantly and helped by the availability of more powerful computing resources. As it requires only 2D images and dedicated processing software, photogrammetry has often been seen as a low-cost alternative to laser scanning (Barsanti et al., 2014; Chiabrando et al., 2015; Evgenikou and Georgopoulos, 2015), even though in many cases both can be complementary; indeed the study of sensor integration is one of the more studied subjects recently (Magda Ramos and Remondino, 2015; Munumer and Lerma, 2015; Murtiyoso et al., 2018). Other alternative low-cost sensors also exist and have been tested for heritage objects, e.g. RGB-D cameras (Lachat et al., 2015).

Photogrammetry for heritage documentation is often employed in its close range configuration, i.e. with images taken from a short distance. This may be done using terrestrial or aerial platforms. The use of DSLR cameras in terrestrial photogrammetry has been much studied, and the general consensus is that as far as non-metric cameras are concerned, DSLR cameras provide the best results (Bedford, 2017) and has even been used for metrological and referential purposes (Börlin et al., 2019; Murtiyoso et al., 2018). However, although DSLR cameras are relatively low-cost in comparison to active sensors, it may still be considered as a "high-end" low cost sensor as far as photographic instruments are involved.

Another disadvantage which is related more to the terrestrial technique than the use of DSLR is that this method has a limited point of view when dealing with building structures. This problem is historically solved using various techniques such as the use of cranes (Achille et al., 2015; Fangi, 2019) or unpowered platforms such as kites and balloons (Verhoeven et al., 2012), but nowadays the use of drones is more commonplace (Grenzdörffer et al., 2015; Hanan et al., 2015; Murtiyoso et al., 2017). When working with drones for close range photogrammetry, a compromise between payload and image quality is often the issue. Higher quality cameras such as a DSLR requires a bigger and heavier (and thus more expensive) drone platform, while lighter and smaller drones can only support lower-quality cameras (Bedford, 2017).

While most of the photographic sensors discussed up to this point refer to classical pin-hole projection camera, there exist other types of lenses with their own advantages and disadvantages. The fish-eye lens has the large disadvantage of having a high level of image distortion; it provides however a much larger field of view. In this way, it may be helpful to survey narrow spaces (Perfetti et al., 2018). Another, extended version, of this fish-eye photogrammetry is the so-called spherical photogrammetry. This technique usually involves the use of equirectangular panoramic $360^{\circ}$ images (Barazzetti et al., 2018; Pramulyo et al., 2017; Ramos and Prieto, 2016). The main interest point in the use of such sensors is its low-cost nature and ease of data acquisition, in expense of image quality. However, the quality of these sensors and therefore the attainable precision has increased in a significant manner these last few years (Barazzetti et al., 2018, 2017).

\section{DATA ACQUISITION AND PROCESSING}

In order to derive useful comments and recommendations, one case study will be considered in this paper. As has been mentioned before, the Buddhist temple Candi Sari in Yogyakarta, Indonesia was used in this case. The Candi Sari dataset is interesting in that the object is not too large, and has been documented using various sensors photogrammetry as well as TLS. In addition, several control points were also measured using a total station, which were used to georeference the data into the national Indonesian projection system. A detailed and more technical description of the documentation project can be consulted in our previous publication (Murtiyoso et al., 2019). For the purposes of this paper, only the exterior of the temple will be considered.

Photogrammetry was conducted using DSLR camera, drone, and the 360 camera (Table 1). For the classical terrestrial photogrammetry, a Canon EOS 5DS R was utilised with a 24 $\mathrm{mm}$ fixed lens. Images were taken from a perpendicular camerato-object distance of around 10 metres; which gives a theoretical Ground Sampling Distance (GSD) of $2 \mathrm{~mm}$ (for objects located directly in front of the camera). More than 500 images were taken, but for the purposes of this experiment, only 100 images converging around the temple's exterior were used. 

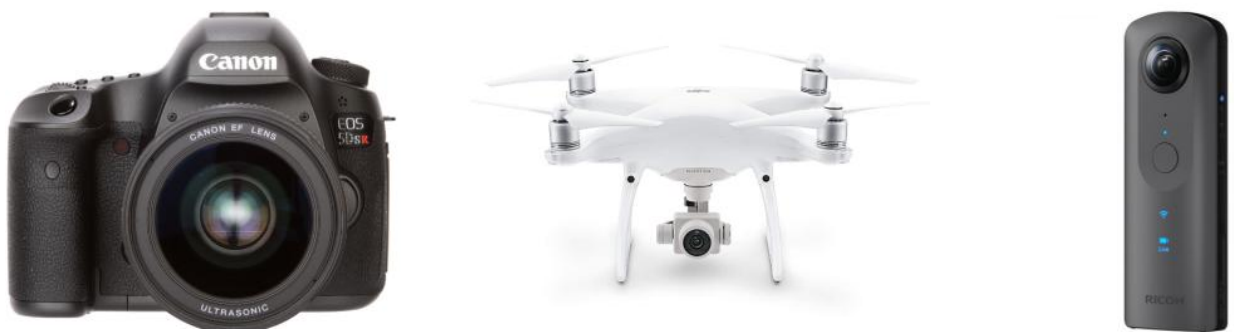

\begin{tabular}{|c|c|c|c|}
\hline Camera name & Canon EOS 5DS R & DJI Phantom 4 & Ricoh Theta V \\
\hline Type & Frame & Frame & Spherical \\
\hline Image resolution & $51 \mathrm{MP}$ & $12 \mathrm{MP}$ & MP \\
\hline Number of images & 100 & 495 & 53 \\
\hline
\end{tabular}

Table 1 . The three photogrammetric sensors used in the case study.

The DJI Phantom 4 was used to take the drone images. The integrated camera possesses a $3.61 \mathrm{~mm}$ lens. With a perpendicular camera-to-object distance of around 7 metres, the GSD of this sensor is in the order of $3 \mathrm{~mm}$ for objects perpendicular to the camera. However, contrary to the terrestrial DSLR acquisition, the use of drones enabled us to take aerial images and thus better homogenise the resulting GSD. A total of 495 drone images were taken of the building's exterior, which consisted of three concentric rings.

Finally, a Ricoh Theta V was used to take the spherical images. This panoramic camera has two fish-eye lenses located back-toback. The included software then transformed the two images taken by these lenses into an equirectangular image by stitching the two fish-eye images. Due to its large field of view, only 53 images were necessary to cover the entirety of the object.

A network of 10 Ground Control Points (GCPs) were scattered on the four façades of the temple. These points take the form of coded targets (CT) to facilitate their identification on the images. Furthermore, another eight detail points were measured from the georeferenced laser scanning point cloud to act as check points (CPs) for the photogrammetric processing. The laser scanning point cloud also served as a reference as regards to the dense matching analysis of the photogrammetric projects.

The laser scanning data was obtained using a terrestrial laser scanner (TLS) Faro Focus M70. This TLS is a phase-based scanner designed for a close range acquisition (from $0.6 \mathrm{~m}$ up to $70 \mathrm{~m}$ as declared by the manufacturer). It has a theoretical precision of $2 \mathrm{~mm}$ for an object located at a distance of $10 \mathrm{~m}^{1}$. The TLS point cloud was then registered and georeferenced using coordinates measured using a total station.

\section{COMPARISON RESULTS}

\subsection{Bundle adjustment}

Orientation results are shown in Figure 1. In order to assess the quality of the bundle adjustment for the three available data sets, comparisons in terms of internal bundle adjustment and external accuracy was performed. The internal precision of the bundle adjustment was assessed from the root-mean-square error of the 3D Euclidean distance residuals of the GCPs, while the external accuracy was determined from a similar procedure but for the residuals of the CPs.

\footnotetext{
${ }^{1}$ https://insights.faro.com/long-range-laser-scanners/techsheet-
} faro-focus-s-m-laser-scanner retrieved on 20 June 2019

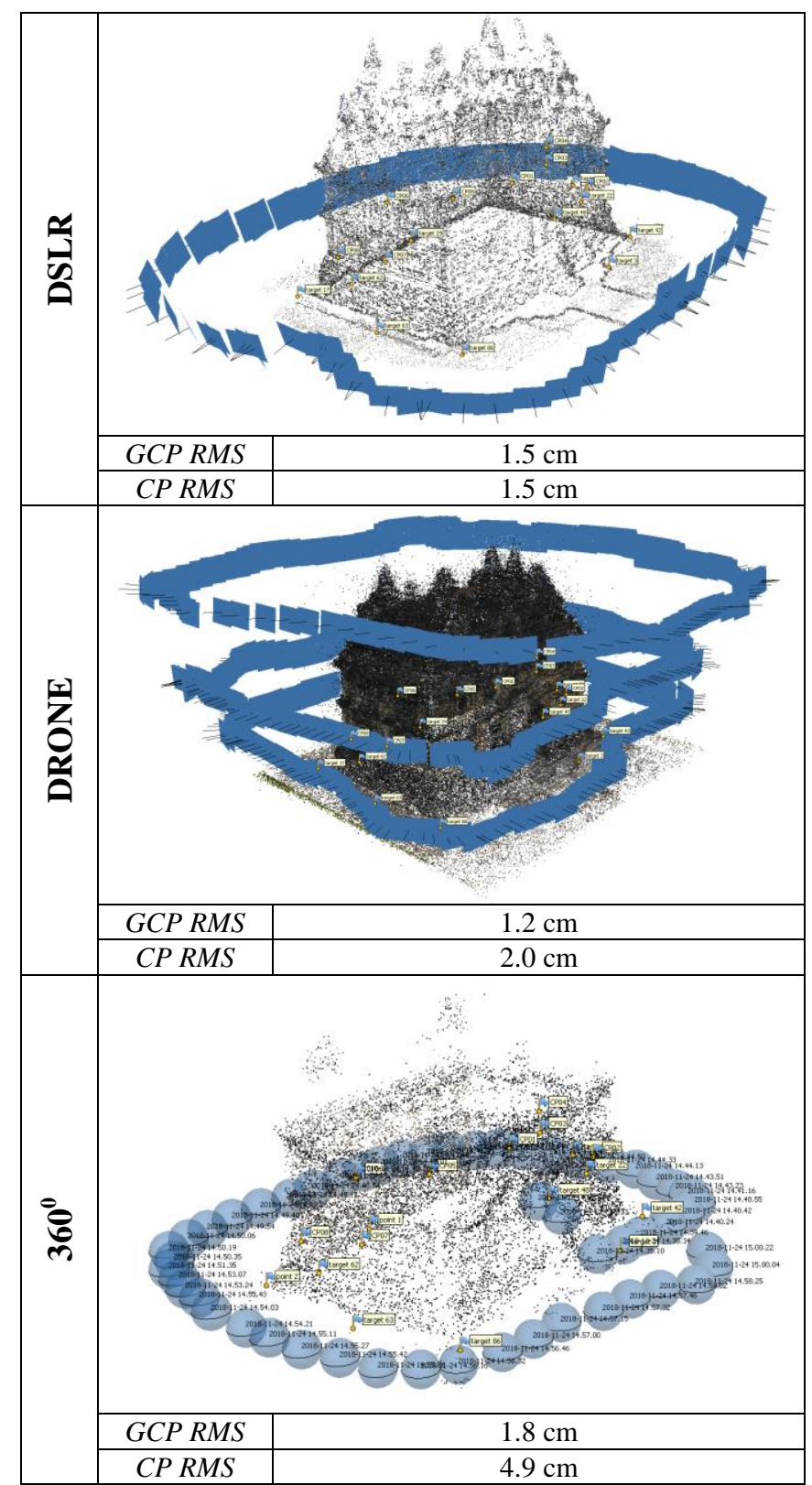

Figure 1. Summary of the bundle adjustment quality as well as illustration of the image and control points network for the three tested data sets. 
Several problems were readily identified during the processing. As has been described before hand, the GCPs in the scene were in the form of CT. This was done mainly to facilitate the identification of the points by benefitting from the software's capability to automatically read CTs. In the case of the $360^{\circ}$ camera, the low resolution images hindered a proper detection of targets. In average, only $20 \%$ of the coded target detection was successful. The problem was worse for targets located in the second storey of the temple, as this fact increases the camera-to-object distance. Consequently, several GCPs had to be manually marked, while two points were wholly impossible to pinpoint. In order to aid this problem, two additional GCPs were added from the TLS point cloud.

As can be seen from the data displayed in Figure 1, the three data sets managed to attain internal bundle adjustment precision of the order of 1 to 2 centimetres. This is in line with the precision of the control points received from the total station and TLS data. The drone data set presented the best result with $1.2 \mathrm{~cm}$ in precision, while the DSLR gave $1.5 \mathrm{~cm}$ and the $360^{\circ}$ camera $1.8 \mathrm{~cm}$. This difference is, however, virtually negligible when considering the centimetric quality of the control point coordinates. It should also be noted that for the $360^{\circ}$ camera, two additional GCPs in the form of detail points were added, as well as the fact that some CT was not identified automatically and thus had to be marked manually. An interesting point to note, however, is the external accuracy as showcased by the $\mathrm{CP}$ RMS. The DSLR managed to get similar value, which denotes an absence of any important systematic error during the bundle adjustment process. The drone data, however, presented a slight discrepancy between internal precision and external accuracy. This may indicate the presence of systematic errors which may be attributed to the absence of proper calibration (all calibration was performed by self-calibration). This proves to be a disadvantage when choosing cameras with smaller sensors. That being said, the discrepancy in the case of the drone remains acceptable $(8 \mathrm{~mm})$. A bigger gap can be observed in the case of the $360^{\circ}$ camera. With an acceptable result of internal precision of $1.8 \mathrm{~cm}$, its external accuracy value jumps to $4.9 \mathrm{~cm}$. This discrepancy is quite significant, and may once again be attributed to the lack of proper calibration and the quality of the sensor.

\subsection{Dense matching}

Another interesting point to observe is the quality of the dense point cloud generated from each data set. The dense matching parameters were homogenised for all three projects. About 16 million points were generated for the DSLR data set, with around 2.8 million for the drone data set and 600 thousand points for the $360^{\circ}$ images. This, however, is to be expected as the number of points depends strongly on the image resolution and amount of images used during the dense matching process.

Visually speaking, the drone data set generated the most complete point cloud. This is also to be expected since the main advantage of using drones in photogrammetry is to access areas otherwise inaccessible by terrestrial photogrammetry e.g. roofs.

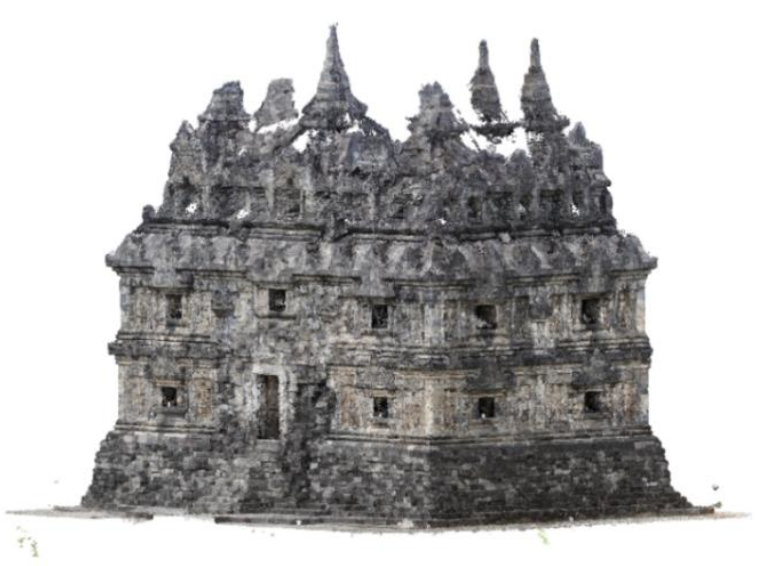

(a)

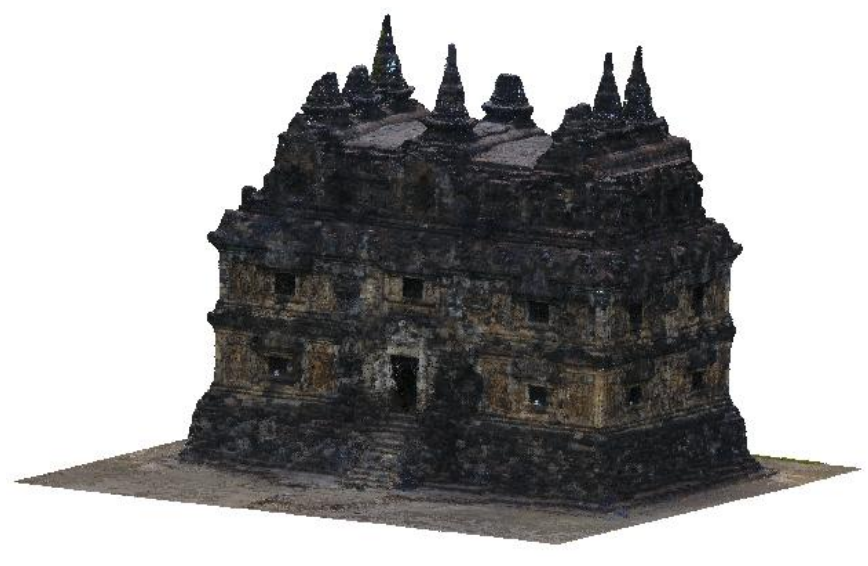

(b)

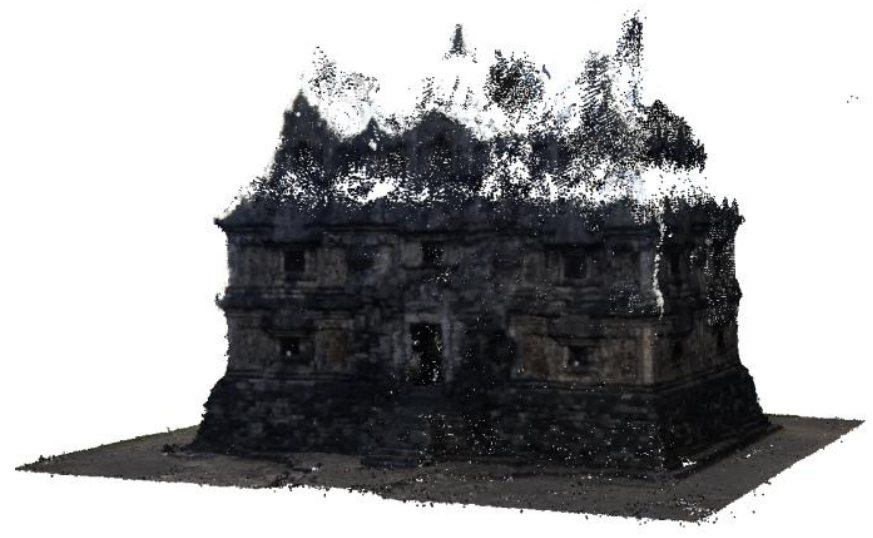

(c)

Figure 2. Dense point cloud results from the three tested sensors: (a) DSLR, (b) drone, and (c) $360^{\circ}$ camera. 


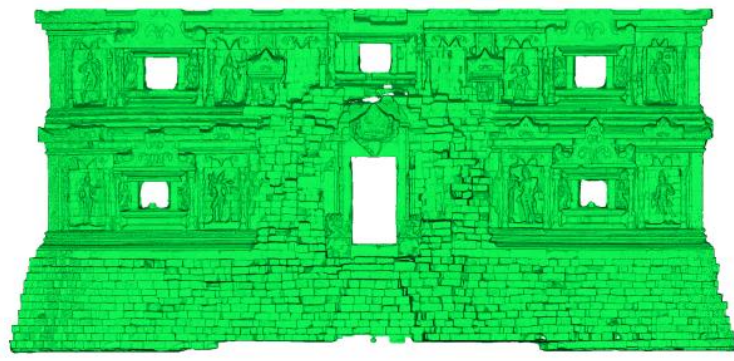

TLS Mesh

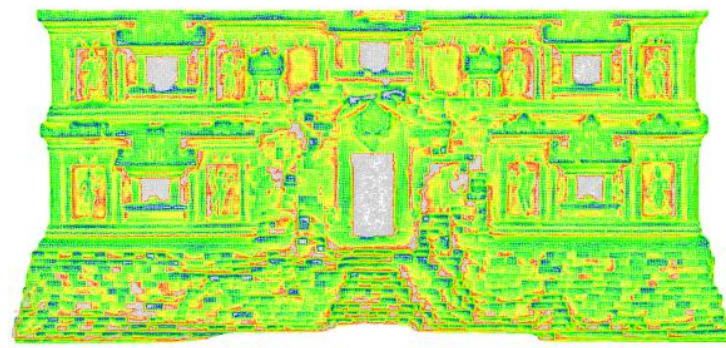

Drone vs TLS Mesh

$\overline{\mathrm{x}}=0.3 \mathrm{~cm} ; \sigma=2.0 \mathrm{~cm} ; 9.00 \%$ out of tolerance

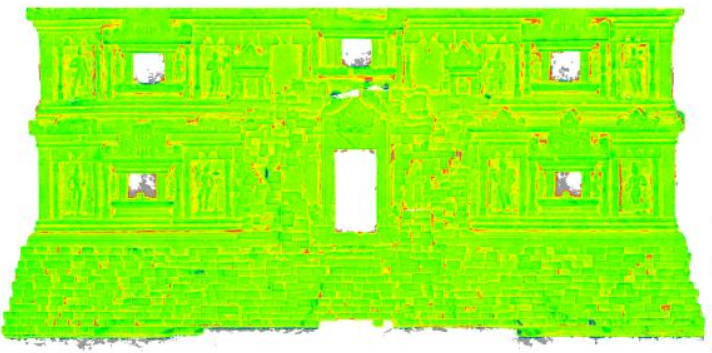

DSLR vs TLS Mesh

$\overline{\mathrm{x}}=0.2 \mathrm{~cm} ; \sigma=1.1 \mathrm{~cm} ; 1.74 \%$ out of tolerance

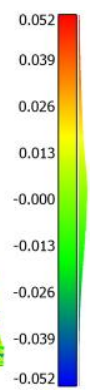

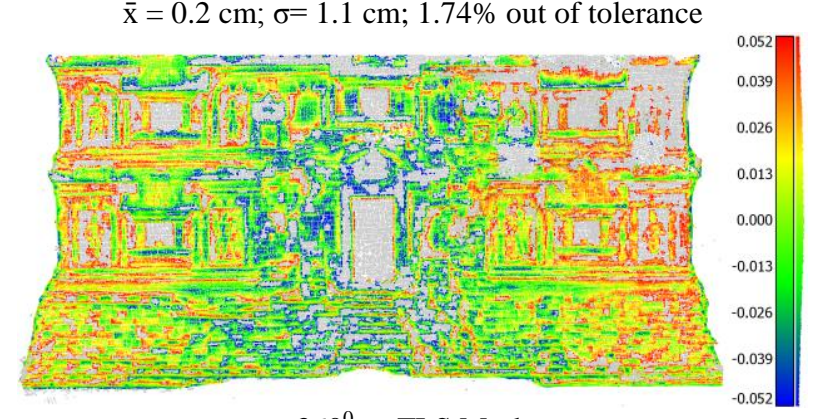

$$
360^{\circ} \text { vs TLS Mesh }
$$

$\overline{\mathrm{x}}=0.2 \mathrm{~cm} ; \sigma=2.7 \mathrm{~cm} ; 26.86 \%$ out of tolerance

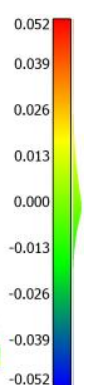

Figure 3. Euclidean distance analysis between the reference (meshed model from TLS point cloud) and the dense point cloud generated from each data set. $\bar{x}$ denotes mean deviation from the reference and $\sigma$ the standard deviation. Grey points are points outside the determined tolerance.

Furthermore, while noise exists in all three data sets, the DSLR point cloud was slightly noisier than the drone, while the $360^{\circ}$ point cloud generated a lot more noise. The fact that the DSLR is noisier can be explained by the fact that the drone image configuration is more robust as it consists of three convergent concentric rings.

In order to get a more quantitative analysis on the dense matching results, an analysis in the CloudCompare software was conducted in which the TLS point cloud was used as a reference. For this purpose and for the sake of simplicity, segmentation was performed on the point clouds of Figure 2 to acquire the point cloud of only the main/front façade of the temple (Figure 3). The said analysis computes the Euclidean 3D distance from each point on the photogrammetric point cloud to its nearest neighbour in the TLS data. A simple point-to-point comparison will generate an absolute value for each distance; this means that a Gaussian curve will not be obtained from such analysis. In order to generate the intended Gaussian distribution curve useful in error analysis, the TLS point cloud was meshed to generate a reference surface. In order to do this, a meshing process was performed using CloudCompare, using the Poisson meshing method. As regards to the level of detail, an octree level of 12 was used during the meshing in order to keep as much as possible the details of the façade.

In order to focus more on the dense matching quality analysis instead of systematic errors pertaining to individual sensors (which may be due, for example, to georeferencing errors), an iterative closest point (ICP) transformation was performed for each of the photogrammetric point cloud using the TLS point cloud as reference. A tolerance was then set to be used in the analysis; in this case we refer to the architectural drawing scale of 1:200 which requires a pixel size of $2 \mathrm{~cm}$. By applying a statistical tolerance of $2.58 \sigma$ ( $99 \%$ level of confidence), the tolerance range was fixed at $\pm 5.2 \mathrm{~cm}$. This means that points whose Euclidean distance towards the reference surface is more than the given tolerance will be considered as outliers. Furthermore, mean deviation and standard deviation values were computed from the resulting Gaussian curve.

Several interesting remarks can be observed from the results of this analysis as shown by Figure 3. First of all, the DSLR data set behaved as expected; it presents the best results with minimal noise (outliers). The standard deviation of the 3D distances is also quite low at $1.1 \mathrm{~cm}$. This is unsurprising since the DSLR possessed a much higher resolution compared to the other two sensors. An interesting observation can rather be seen on the other two data sets. For the drone, despite the nice visual preliminary inspection of the dense point cloud, near to $10 \%$ of its points are considered as outliers. The distance deviations are more distributed, with a standard deviation almost twice that of the DSLR. The $360^{\circ}$ point cloud fared worse, with a standard deviation value amounting to almost $3 \mathrm{~cm}$ and near to $30 \%$ of its points considered out of tolerance. The relative comparison between the three data sets showed nothing surprising, considering the quality of the respective sensors. However, this information is useful in determining which low-cost sensor is best to be used for which purpose.

\section{CONCLUDING REMARKS}

This paper has attempted to better understand the performance of several photogrammetric sensors which are considered as low-cost. Three sensors were tested, ranging from the higherend low-cost DSLR camera, to a drone sensor, and a $360^{\circ}$ camera. The results show that each sensor has their own advantages and disadvantages, and there are important points to remember when using one for a specific purpose in the documentation of heritage objects and sites. From these technical observations, some considerations will be proposed in this section in terms of data acquisition as well as the results. 


\subsection{Considerations for data acquisition}

Concerning data acquisition, photogrammetry has always been less "user-friendly" than TLS. As has been described in this paper, prior knowledge is required in order to get decent results from photogrammetry. This includes proper image configuration (e.g. convergent vs. parallel), rules regarding focal lengths, calculations related to the required ground sampling distance, as well as some knowledge in photography. While the low-cost nature of photogrammetry offers an interesting compromise in this regard, prior knowledge on basic photogrammetric rules are nevertheless very important. However, also as has been shown in the paper, different types of photogrammetric sensors give different advantages related to the data acquisition. The DSLR and drone data acquisition stage followed the traditional close range photogrammetry pipeline; however the use of drones can be seen as very advantageous in covering inaccessible parts (e.g. roofs). The $360^{\circ}$ camera is the most interesting option as far as data acquisition is concerned. The possibility to acquire large swaths of image in a single image drastically reduces the number of images required to be taken, and therefore also reduces the acquisition time. Basic photogrammetric rules must still be respected (overlap between images, photographic setting, etc.), but one cannot deny the significant advantage this type of sensor has in terms of data acquisition process.

Drones have been cited as being very useful to acquire images from difficult angles. The recent boom has also helped to democratise drones, to the point of making this type of sensor fairly low-cost even as compared to a DSLR camera. However, drones also have limitations in terms of data acquisition. This involves mainly the requirement for an open space for the takeoff/landing, as well as sufficiently enough space in front of the object for the drone to fly. Another very important issue that has seen much development in many countries recently is the issue of permits and authorisations. Depending on the local regulations, drone flight may be difficult to perform or even outright impossible. Drone survey for close range photogrammetry also requires proper crowd management to inform and limit the public from intervening during the image acquisition. Another issue is the compromise between larger, more expensive platforms suitable for better lenses, and smaller but less costly platforms with poorer sensors.

The issue of camera calibration has been evoked during the paper. While the DSLR works fairly well with self-calibration, the drone and $360^{\circ}$ sensors were shown to may have to benefit from better geometric camera calibration to improve their results. However we note also that the convergent image configuration of the DSLR also aids the self-calibration process. A dedicated calibration does not necessarily remove the lowcost label from these sensors, but does add to the required knowledge and skills in performing it.

\subsection{Considerations for results}

The tests conducted in this paper showed the extent of the quality of the results from the three sensors. In terms of bundle adjustment, we see a very promising result even for the $360^{\circ}$ camera. As bundle adjustment quality is strongly related to the geometric quality of the project, this illustrates the feasibility of each respective camera to perform dimensional measurements on the object. The DSLR has shown to be the most stable solution in this regard, although surprisingly enough the lowercost sensor of the drone managed to attain a comparable result. The $360^{\circ}$ camera also fared well in this regard, although both drone and $360^{\circ}$ camera suffered from some systematic error. For heritage documentation purposes, the drone and DSLR systems are very much sufficient. The $360^{\circ}$ camera may require further calibration and fine-tuning to get to the same precision level; however the results are very promising.

On the subject of dense matching, the quality of the sensor started to show its influences. The DSLR managed to match, if not surpass, the TLS in terms of dense point cloud details. The drone sensor already showed degradation in dense point quality, although it may still be acceptable for some applications. The $360^{\circ}$ dense point cloud presented the worst results. Dense point cloud quality generally represents the level of detail required from a 3D model. In this regard, the DSLR still leads in terms of details represented. Indeed, the test show that the DSLR result can very well be used to create 1:200, or even 1:100 architectural drawings (shorter distance arrangement should be made to create a 1:50 drawing). Depending on the application, the other results may also be sufficient also. The drone point cloud is of a perfect quality for 3D GIS and mapping purposes. It may also be used to create 1:200 drawings, although as has been shown it will definitely be of a lower quality from the DSLR one. The $360^{\circ}$ data at the moment is still only fit for visualisation purposes and even then, heavy image masking and point cloud cleaning must be performed before hand.

Another point to consider is the choice of software. The tests and processing in this paper was performed using the Agisoft MetaShape commercial software. Other open source alternatives also exist, however at the moment not a lot of software solutions offer the possibility to compute different camera modes (frame, fish-eye, and especially spherical). To the best of our knowledge, some of the software solutions which permits the computation of spherical photogrammetry other than MetaShape are Pix4D (Barazzetti et al., 2017) and the open source MicMac (Rupnik et al., 2017).

\subsection{General considerations}

In general, photogrammetry presented a very interesting lowcost solution for the 3D documentation of heritage sites. However, as has been described in this paper, several general points should be considered for its use:

1. The choice of sensors is very important and should be adapted to the objective of the project (architectural drawing, SIG, VR/AR, etc.).

2. Adequate knowledge and training are required in order to generate good results from photogrammetry.

3. As far as bundle adjustment is concerned, all the three tested sensors showed good and promising results. Precision of the control point network is an important aspect to take into account, as it is directly linked to the geometric quality.

4. The DSLR remains a benchmark in photogrammetry as far as dense matching is concerned, but drones are useful to complete the 3D data. In this regard, the choice of the sensor once again becomes an important aspect.

5. $360^{\circ}$ cameras present interesting and promising results, but further refinement as well as eventually camera calibration should be considered to improve the results.

6. The choice of the software may also be an important aspect when targeting a low-cost project. Open source solutions exist in the market; however, it has not been adequately assessed in this paper. 


\section{ACKNOWLEDGEMENTS}

This research is part of the Franco-Indonesian Partenariat Hubert-Curien (PHC) NUSANTARA program under the aegis of the Indonesian Ministry of Research and Higher Education (KEMENRISTEKDIKTI), the French Ministry for Europe and Foreign Affairs (MEAE), and the French Ministry of Higher Education, Research, and Innovation (MESRI). The authors also wish to thank our colleagues in the Yogyakarta Archaeological Bureau, namely Sugeng Riyanto, and the Central Java Heritage Conservation Bureau for their help in facilitating the acquisition mission and in obtaining the necessary authorisations.

\section{REFERENCES}

Achille, C., Adami, A., Chiarini, S., Cremonesi, S., Fassi, F., Fregonese, L., Taffurelli, L., 2015. UAV-based photogrammetry and integrated technologies for architectural applications methodological strategies for the after-quake survey of vertical structures in Mantua (Italy). Sensors 15, 15520-15539.

Barazzetti, L., Previtali, M., Roncoroni, F., 2018. Can we use low-cost 360 degree cameras to create accurate 3D models? Int. Arch. Photogramm. Remote Sens. Spatial Inf. Sci., XLII-2, 69-75. doi.org/10.5194/isprs-archives-XLII-2-69-2018

Barazzetti, L., Previtali, M., Roncoroni, F., 2017. 3D modelling with the samsung gear 360. Int. Arch. Photogramm. Remote Sens. Spatial Inf. Sci., XLII-2/W3, 85-90. doi.org/ 10.5194/isprs-archives-XLII-2-W3-85-2017

Barazzetti, L., Previtali, M., Roncoroni, F., Valente, R., 2019. Connecting inside and outside through $360^{\circ}$ imagery for closerange photogrammetry. ISPRS Ann. Photogramm. Remote Sens. Spatial Inf. Sci., XLII-2/W9, 87-92. doi.org/ 10.5194/isprsarchives-XLII-2-W9-87-2019

Barsanti, S.G., Remondino, F., Fenández-Palacios, B.J., Visintini, D., 2014. Critical factors and guidelines for 3D surveying and modelling in Cultural Heritage. International Journal of Heritage in the Digital Era 3, 141-158.

Bedford, J., 2017. Photogrammetric Applications for Cultural Heritage. Historic England, Swindon.

Börlin, N., Murtiyoso, A., Grussenmeyer, P., Menna, F., Nocerino, E., 2019. Flexible Photogrammetric Computations Using Modular Bundle Adjustment: The Chain Rule and the Collinearity Equations. Photogrammetric Engineering \& Remote Sensing 85, 361-368.

Chiabrando, F., Donadio, E., Rinaudo, F., 2015. SfM for orthophoto generation: a winning approach for cultural heritage knowledge. Int. Arch. Photogramm. Remote Sens. Spatial Inf. Sci., XL-5/W7, 91-98, doi.org/10.5194/isprsarchives-XL-5-W791-2015.

Chiabrando, F., Lo Turco, M., Santagati, C., 2017. Digital invasions: From point clouds to historical building object modeling (H-BOM) of a UNESCO WHL site. Int. Arch. Photogramm. Remote Sens. Spatial Inf. Sci., XLII-2/W3, 171178, doi.org/10.5194/isprs-archives-XLII-2-W3-171-2017.

Degroot, V., 2009. Candi, Space and Landscape: A Study on the Distribution, Orientation and Spatial Organization of Central Javanese Temple Remains, Mededeling. ed. Sidestone Press, Leiden.

Evgenikou, V., Georgopoulos, A., 2015. Investigating 3D reconstruction methods for small artifacts. Int. Arch. Photogramm. Remote Sens. Spatial Inf. Sci., XL-5/W4, 101108, doi.org/10.5194/isprsarchives-XL-5-W4-101-2015.

Fangi, G., 2019. Aleppo - Before and after. Int. Arch. Photogramm. Remote Sens. Spatial Inf. Sci., XLII-2/W9, 333338, doi.org/10.5194/isprs-archives-XLII-2-W9-333-2019.

Farella, E.M., Torresani, A., Remondino, F., 2019. Quality Features for the Integration of Terrestrial and UAV Images. Int. Arch. Photogramm. Remote Sens. Spatial Inf. Sci., XLII-2/W9, 339-346, doi.org/10.5194/isprs-archives-XLII-2-W9-339-2019.

Grenzdörffer, G.J., Naumann, M., Niemeyer, F., Frank, A., 2015. Symbiosis of UAS Photogrammetry and TLS for Surveying and 3D Modeling of Cultural Heritage Monuments a Case Study About the Cathedral of St. Nicholas in the City of Greifswald. Int. Arch. Photogramm. Remote Sens. Spatial Inf. Sci., XL-1/W4, 91-96, doi.org/10.5194/isprsarchives-XL-1-W491-2015.

Hanan, H., Suwardhi, D., Nurhasanah, T., Bukit, E.S., 2015. Batak Toba Cultural Heritage and Close-range Photogrammetry. Procedia - Social and Behavioral Sciences 184, 187-195.

Herbig, U., Stampfer, L., Grandits, D., Mayer, I., Pöchtrager, M., Setyastuti, A., 2019. Developing a Monitoring Workflow for the Temples of Java. Int. Arch. Photogramm. Remote Sens. Spatial Inf. Sci., XLII-2/W15, 555-562, doi.org/10.5194/isprsarchives-XLII-2-W15-555-2019.

Hidayat, H., Cahyono, A.B., 2016. Digital Reconstruction of Singosari Temple Using Structure From Motion Methods. Geoid 11, 211-218.

Lachat, E., Landes, T., Grussenmeyer, P., 2017. Investigation of a combined surveying and scanning device: The Trimble SX10 $\begin{array}{llll}\text { scanning total station. } & \text { Sensors 17, }\end{array}$ doi.org/10.3390/s17040730

Lachat, E., Macher, H., Landes, T., Grussenmeyer, P., 2015. Assessment and calibration of a RGB-D camera (Kinect v2 Sensor) towards a potential use for close-range 3D modeling. Remote Sensing 7, 13070-13097. doi.org/10.3390/rs71013070

Magda Ramos, M., Remondino, F., 2015. Data fusion in cultural heritage - A review. Int. Arch. Photogramm. Remote Sens. Spatial Inf. Sci., XL-5/W7, 359-363, doi.org/10.5194/isprsarchives-XL-5-W7-359-2015.

Munumer, E., Lerma, J.L., 2015. Fusion of 3D data from different image-based and range-based sources for efficient heritage recording, in: 2015 Digital Heritage. pp. 83-86.

Murtiyoso, A., Grussenmeyer, P., 2017. Documentation of heritage buildings using close-range UAV images: dense matching issues, comparison and case studies. The Photogrammetric Record 32, 206-229.

Murtiyoso, A., Grussenmeyer, P., Suwardhi, D., Awalludin, R., 2018. Multi-Scale and Multi-Sensor 3D Documentation of Heritage Complexes in Urban Areas. ISPRS International Journal of Geo-Information, 7(12), 483. doi.org/10.3390/ijgi7120483

Murtiyoso, A., Grussenmeyer, P., Suwardhi, D., Fadilah, W.A., Permana, H.A., Wicaksono, D., 2019. Multi-Sensor 3D Recording Pipeline for the Documentation of Javanese Temples. Int. Arch. Photogramm. Remote Sens. Spatial Inf. Sci., XLII-2/W15, 829-834, doi.org/10.5194/isprs-archives- 


\section{XLII-2-W15-829-2019.}

Murtiyoso, A., Koehl, M., Grussenmeyer, P., Freville, T., 2017. Acquisition and Processing Protocols for UAV Images: 3D Modeling of Historical Buildings using Photogrammetry. ISPRS Ann. Photogramm. Remote Sens. Spatial Inf. Sci., IV2/W2, 163-170, doi.org/10.5194/isprs-annals-IV-2-W2-1632017.

Perfetti, L., Polari, C., Fassi, F., Troisi, S., Baiocchi, V., Del Pizzo, S., Giannone, F., Barazzetti, L., Previtali, M., Roncoroni, F., 2018. Fisheye Photogrammetry to Survey Narrow Spaces in Architecture and a Hypogea Environment, in: Latest Developments in Reality-Based 3D Surveying and Modelling; Remondino, F., Georgopoulos, A., González-Aguilera, D., Agrafiotis, P., Eds.; MDPI: Basel, Switzerland, 3-28.

Pöchtrager, M., Styhler-Aydın, G., Döring-Williams, M., Pfeifer, N., 2018. Digital reconstruction of historic roof structures: developing a workflow for a highly automated analysis. Virtual Archaeology Review 9, 21.

Pramulyo, H., Harto, A.B., Mertotaroeno, S.H., Murtiyoso, A., 2017. Towards better 3D model accuracy with spherical photogrammetry. In: The Rise of Big Spatial Data. Lecture Notes in Geoinformation and Cartography; Ivan I., Singleton A., Horák J., Inspektor T., Eds. Springer, Cham, pp.107-120. doi.org/10.1007/978-3-319-45123-7_8

Ramos, A.P., Prieto, G.R., 2016. Only image based for the 3D metric survey of gothic structures by using frame cameras and panoramic cameras. Int. Arch. Photogramm. Remote Sens. Spatial Inf. Sci., XLI-B5, 363-370, doi.org/10.5194/isprsarchives-XLI-B5-363-2016.

Rupnik, E., Daakir, M., Pierrot Deseilligny, M., 2017. MicMac - a free, open-source solution for photogrammetry. Open Geospatial Data, Software and Standards 2, 14.

Suwardhi, D., Menna, F., Remondino, F., Hanke, K., Akmalia, R., 2015. Digital 3D Borobudur - Integration of 3D Surveying and Modeling Techniques. Int. Arch. Photogramm. Remote Sens. Spatial Inf. Sci., XL-5/W7, 417-423, doi.org/10.5194/isprsarchives-XL-5-W7-417-2015.

Verhoeven, G., Taelman, D., Vermeulen, F., 2012. Computer Vision-Based Orthophoto Mapping Of Complex Archaeological Sites: The Ancient Quarry Of Pitaranha (Portugal-Spain). Archaeometry 54, 1114-1129. 